\title{
Analysis of risk factors and treatment outcome following methotrexate therapy in ectopic pregnancy
}

\author{
Paneerselvam Amudha, Shenbagam G., Raji C.*
}

Department of Obstetrics and Gynecology, Government Medical College, Pudukkottai, Tamil Nadu, India

Received: 15 January 2022

Revised: 30 January 2022

Accepted: 31 January 2022

\section{*Correspondence:}

Dr. Raji C.,

E-mail: drrajeesekar@gmail.com

Copyright: ( $)$ the author(s), publisher and licensee Medip Academy. This is an open-access article distributed under the terms of the Creative Commons Attribution Non-Commercial License, which permits unrestricted non-commercial use, distribution, and reproduction in any medium, provided the original work is properly cited.

\section{ABSTRACT}

Background: Ectopic pregnancy is a significant cause of morbidity and mortality in first trimester of pregnancy. Awareness regarding risk factors for ectopic pregnancy aids in early diagnosis and timely medical intervention before tubal rupture occurs. This study was undertaken to analyze the risk factors for ectopic pregnancy and to study the treatment outcome following methotrexate therapy.

Methods: In this prospective study, 34 women with unruptured ectopic pregnancy selected for medical therapy were enrolled women with ectopic pregnancy who were hemodynamically stable with initial beta-human chorionic gonadotropin $(\beta \mathrm{hCG})$ values of $<5000 \mathrm{mIU} / \mathrm{l}$, ectopic gestation mass size $<5 \mathrm{~cm}$ and with no contraindication for methotrexate use were included in the study. Risk factors for ectopic pregnancy were studied and treatment outcome following single dose or 2 dose methotrexate regimen were analyzed.

Results: The mean age of the study group was $26.88 \pm 4.5$ years. Highest incidence of ectopic pregnancy was noted in 26-30 years and in second gravidas. Successful treatment outcome was observed in $61.8 \%$ with single dose methotrexate (MTX) and in $23.5 \%$ with 2 doses. Overall success rate of MTX therapy was $85.3 \%$. Surgical intervention was instituted in $14.7 \%$ when pretreatment $\beta$ hCG levels were $<1500 \mathrm{mIU} / \mathrm{ml}$. Single dose MTX was successful in $91.7 \%$ and with 2 doses it was $100 \%$. None developed any major side effects to methotrexate therapy.

Conclusions: MTX therapy is safe and effective in carefully selected women with ectopic pregnancy. Success rate of MTX therapy was $85.3 \%$. MTX was most effective when pretreatment $\beta$ hCG levels were less than $1500 \mathrm{mIU} / \mathrm{ml}$.

Keywords: Ectopic pregnancy, Risk factors, Methotrexate

\section{INTRODUCTION}

Despite advances in diagnosis and management, ectopic pregnancy (EP) is one of the significant causes of maternal mortality in early weeks of pregnancy. ${ }^{1}$ The incidence of EP in India ranges from $1-2 \% .^{2}$ Maternal mortality due to EP varies from none to $3.5 \%$ and reflects the variable quality of medical infrastructure facilities available in the country. ${ }^{3}$ Late diagnosis and delay in accessing medical care are important causes of deaths due to EP.

Nearly about $50 \%$ of women diagnosed with EP do not have any known risk factors. ${ }^{4}$ However, those with significant risk factors should be evaluated for possible EP even in the absence of symptoms. ${ }^{5}$ Clinical presentation and serum beta-human chorionic gonadotropin ( $\beta$ hCG) levels along with reliable sonographic findings like adnexal mass with features of early pregnancy such as a gestational sac with yolk sac or fetal pole with or without cardiac activity should be used to confirm or rule out EP. ${ }^{6}$ However, most pregnancies do not progress to this stage. ${ }^{7}$ Women with confirmed or high clinical suspicion of EP who are hemodynamically stable with unruptured ectopic mass and who do not have any absolute contraindications to methotrexate (MTX) are ideal candidates for medical therapy. The decision for medical therapy should be 
guided by clinical, laboratory and radiological data as well as by patient informed choice. ${ }^{5}$

This study was undertaken to have a better understanding of risk factors for EP in our population and to analyze the outcome of medical therapy in a carefully selected group of women with EP.

\section{METHODS}

This prospective study was conducted in Government Medical College Hospital, Pudukottai in South India between January 2021 and December 2021. All women diagnosed with EP and selected for medical management were enrolled in the study. Women enrolled were counselled about the benefits and risks involved and informed consent was obtained. EP was diagnosed based on specific clinical features, ultrasound findings and serial $\beta$ hCG values.

Women who were hemodynamically stable, with no evidence of hemoperitoneum, adnexal mass of $<5 \mathrm{~cm}$, absent fetal cardiac activity, $\beta$ hCG level of $<5000 \mathrm{mIU} / \mathrm{ml}$ and mild abdominal pain were included in the study.

Exclusion criteria were non-tubal EP, hemodynamic instability, evidence of intraperitoneal bleeding, moderate to severe anaemia, hepatic or renal dysfunction, sensitivity to MTX, blood dyscrasias, pulmonary disease, thrombocytopenia, immuno-compromised state, adnexal mass of $>5 \mathrm{~cm}$ and $\beta$ hCG level of $>5000 \mathrm{mIU} / \mathrm{ml}$. Details of risk factors for EP were noted. Baseline blood investigations like complete blood count, liver function tests and renal function tests were done.

All women received injection MTX $50 \mathrm{mg} / \mathrm{m}^{2}$ intramuscularly. Serial $\beta$ hCG estimations were done on day 1,4 and 7 . Post administration, women were monitored for symptoms and signs of rupture of EP and side effects of MTX. Ultrasound examination was done if any woman became symptomatic with increasing abdominal pain or if there is suboptimal decline $(<15 \%)$ of $\beta \mathrm{hCG}$ on day 7 . If the decline in $\beta$ hCG level on day 7 was $>15 \%$, then weekly estimations were done until it was $<15$ $\mathrm{mIU} / \mathrm{ml}$. Those with suboptimal fall in $\beta$ hCG levels on day 7 were either given a $2^{\text {nd }}$ dose of MTX after excluding ectopic fetal cardiac activity and hemoperitoneum or taken up for surgical intervention based on the trend of $\beta$ hCG and ultrasound findings. Those given a second dose of MTX were followed up with repeat $\beta$ hCG estimation on day 11 . Side effects of MTX if any were noted.

\section{Statistical analysis}

Data were entered in the excel spreadsheet and variables were coded accordingly. The statistical analyses were performed using Graph pad Prism version 5 software. Data were presented as frequency with proportion $\mathrm{n}(\%)$ for categorical data.

\section{RESULTS}

The mean age of the study group was $26.8 \pm 4.5$ years with a range of 17-36 years (Table 1). Maximum incidence (41.2\%) of EP was noted in the 26-31 years age group and in second gravidas (Table 2) which was statistically significant (Table 3). In $26.5 \%(n=9)$ EP was the first conception.

Table 1: Ectopic pregnancy in relation to age.

\begin{tabular}{|llll|}
\hline S. no. & $\begin{array}{l}\text { Age category } \\
\text { (years) }\end{array}$ & $\mathbf{n = 3 4}$ & $\%$ \\
\hline $\mathbf{1}$ & $\leq 20$ & 3 & 8.8 \\
\hline $\mathbf{2}$ & $22-25$ & 10 & 29.4 \\
\hline $\mathbf{3}$ & $26-30$ & 14 & 41.2 \\
\hline $\mathbf{4}$ & $31-35$ & 6 & 17.6 \\
\hline $\mathbf{5}$ & $>35$ & 1 & 2.9 \\
\hline
\end{tabular}

Data are expressed as $\mathrm{n}$ with proportions (\%), total $\mathrm{n}=34$

Table 2: Distribution of cases based on parity.

\begin{tabular}{|llll|}
\hline S. no. & Parity & n=34 & \% \\
\hline $\mathbf{1}$ & Nullipara & 9 & 26.5 \\
\hline $\mathbf{2}$ & Para 1 & 14 & 41.2 \\
\hline $\mathbf{3}$ & Para 2 & 9 & 26.5 \\
\hline $\mathbf{4}$ & Para 3 & 2 & 5.8 \\
\hline
\end{tabular}

Data are expressed as $n$ with proportions $(\%)$, total $n=34$. On review of previous reproductive performance, incidence of ectopic gestation $(41.2 \%)$ was higher in second gravidas

On analysis of risk factors, 19 out of $34(55.9 \%)$ women had 1 or more risk factors for EP. Four women had undergone tubal surgeries and 5 non tubal pelvic surgeries, 4 had been treated for infertility, 1 had a prior medically managed ectopic gestation, 3 had prior abortions, 2 had history of prior intra uterine device (IUD) use and 2 gave history of pelvic inflammatory disease (Table 4). Fifteen women had no identifiable risk factor for EP.

On analyzing the initial $\beta$ hCG level and treatment outcome (Table 5), $91.7 \%(11 / 12)$ responded to single dose of MTX when $\beta$ hCG levels were $<1500 \mathrm{mIU} / \mathrm{ml}$. In women with $\beta$ hCG levels between 1500 and 3000 $\mathrm{mIU} / \mathrm{ml}, 80 \%(8 / 10)$ responded to single dose and only $20 \%(2 / 10)$ required an additional dose of whom 1 required surgery. On the contrary, in those with $\beta$ hCG levels more than $3000 \mathrm{mIU} / \mathrm{ml}, 83.3 \%(10 / 12)$ required an additional dose, of whom $4(33.3 \%)$ had to undergo surgery. The success rate of MTX therapy was $100 \%$ when $\beta$ hCG levels were $<1500 \mathrm{mIU} / \mathrm{ml}, 90 \%$ when $\beta$ hCG levels were between 1500 and $3000 \mathrm{mIU} / \mathrm{ml}$ and it dipped to $66.7 \%$ when $\beta$ hCG levels were above $3000 \mathrm{mIU} / \mathrm{ml}$.

On analysis of factors favoring successful treatment outcome, 28 had an adnexal mass of $<3.5 \mathrm{~cm}$ and in 6 it was $>3.5 \mathrm{~cm}$. Twenty one out of $28(75 \%)$ with an adnexal mass of $<3.5 \mathrm{~cm}$ were successfully treated with single dose MTX while $5(17.9 \%)$ responded to an additional dose and 
$2(7.1 \%)$ required surgery. All 6 women (100\%) with adnexal mass of $>3.5 \mathrm{~cm}$ required an additional dose of MTX of whom $50 \%(n=3)$ required surgical intervention. The success rate of MTX therapy for EP was $93 \%$ when the adnexal mass was $<3.5 \mathrm{~cm}$ and it fell to $50 \%$ in those with adnexal mass of $>3.5 \mathrm{~cm}$ (Table 6 ).
The overall success rate of MTX therapy in our study was $85.3 \%$ (29/34). Five women (14.7\%) needed emergency surgical intervention of whom 1 had developed intraperitoneal haemorrhage and 4 had plateauing/increasing levels of $\beta$ hCG after the additional dose of MTX.

Table 3: Correlation of the cases by age and parity.

\begin{tabular}{|llllllllll|}
\hline S. no & $\begin{array}{l}\text { Gestational age } \\
\text { category (years) }\end{array}$ & \multicolumn{2}{c}{ Primigravida $(\mathbf{n}=\mathbf{9})$} & \multicolumn{2}{c|}{ Gravida-2 $(\mathbf{n}=\mathbf{1 4})$} & \multicolumn{2}{c|}{ Gravida-3 $(\mathbf{n}=\mathbf{9})$} & \multicolumn{2}{c|}{ Gravida-4 $(\mathbf{n}=\mathbf{2})$} \\
\hline $\mathbf{1}$ & $\leq 20$ & 3 & $\mathbf{\%}$ & $\mathbf{n}$ & $\mathbf{\%}$ & $\mathbf{n}$ & $\mathbf{\%}$ & $\mathbf{n}$ & $\mathbf{\%}$ \\
\hline $\mathbf{2}$ & $21-25$ & 5 & 33.3 & 0 & 0 & 0 & 0 & 0 & 0 \\
\hline $\mathbf{3}$ & $26-30$ & 1 & 55.6 & 5 & 35.7 & 0 & 0 & 0 & 0 \\
\hline $\mathbf{4}$ & $31-35$ & 0 & 11.1 & 7 & 50 & 5 & 55.6 & 1 & 50 \\
\hline $\mathbf{5}$ & $>35$ & 0 & 0 & 0 & 0 & 1 & 11.1 & 0 & 0 \\
\hline
\end{tabular}

Chi square value $=23.47 ; \mathrm{df}=12$ and $\mathrm{p}$ value $=0.024^{*}$, data are expressed as $\mathrm{n}$ with proportions $(\%)$, total $\mathrm{n}=34,{ }^{*} \mathrm{p}<0.05$ is significant

Table 4: Risk factors for ectopic pregnancy observed in study population.

\begin{tabular}{|c|c|c|c|c|}
\hline S. no & Risk factors & Break up of risk factors & $\mathbf{n}$ & $\%$ \\
\hline \multirow{2}{*}{1} & \multirow{2}{*}{ Prior ectopic gestation } & Medically treated ectopic gestation -1 & \multirow{2}{*}{2} & \multirow{2}{*}{5.9} \\
\hline & & Surgically managed ectopic gestation -1 & & \\
\hline 2 & Prior abortions & Spontaneous first trimester abortions -3 & 3 & 8.8 \\
\hline \multirow{4}{*}{3} & \multirow{4}{*}{ Tubal surgery } & Laparoscopic sterilization - 1 & \multirow{4}{*}{4} & \multirow{4}{*}{11.8} \\
\hline & & Tubal sterilization -1 & & \\
\hline & & Tubal re-canalisation -1 & & \\
\hline & & Partial salpingectomy for adnexal torsion -1 & & \\
\hline \multirow{2}{*}{4} & \multirow{2}{*}{ Non tubal pelvic surgeries } & Caesarean section -4 & \multirow{2}{*}{5} & \multirow{2}{*}{14.7} \\
\hline & & Appendicectomy - 1 & & \\
\hline \multirow{4}{*}{5} & \multirow{4}{*}{ Infertility } & Ovulation induction -1 & \multirow{4}{*}{4} & \multirow{4}{*}{11.18} \\
\hline & & Ovulation induction and artificial insemination -1 & & \\
\hline & & Assisted reproductive technique -1 & & \\
\hline & & Untreated infertility -1 & & \\
\hline 6 & Intrauterine device use & Prior multiload $\mathrm{Cu} \mathrm{T}$ use -2 & 2 & 5.9 \\
\hline 7 & Pelvic inflammatory disease & & 2 & 5.9 \\
\hline
\end{tabular}

Data are expressed as 'n' with proportions (\%). 19/34 women were identified to have 1 or more risk factors

Table 5: Analysis of initial $\beta$-hCG level and treatment outcome.

\begin{tabular}{|c|c|c|c|c|c|c|c|}
\hline $\begin{array}{l}\text { S. } \\
\text { no. }\end{array}$ & $\begin{array}{l}\text { Initial } \beta \text {-hCG level on } \\
\text { admission (mIU/ml) }\end{array}$ & $\begin{array}{l}\text { No of } \\
\text { cases } \\
n=34\end{array}$ & $\begin{array}{l}\text { Single } \\
\text { dose } \\
\mathrm{n}=\mathbf{2 1}\end{array}$ & $\begin{array}{l}\text { Multiple } \\
\text { dose } \\
\mathrm{n}=\mathbf{1 3}\end{array}$ & $\begin{array}{l}\text { Success } \\
\text { rate } \\
n=29\end{array}$ & $\begin{array}{l}\text { MTX } \\
\text { treatment } \\
\text { success } \% \\
\end{array}$ & $\begin{array}{l}\text { MTX treatment } \\
\text { failure } 14.7 \% \\
(n=5)\end{array}$ \\
\hline 1 & $<1500$ & 12 & 11 & 1 & 12 & 100 & - \\
\hline 2 & 1500 to 3000 & 10 & 8 & 2 & 9 & 90 & 1 \\
\hline 3 & 3000 to 5000 & 12 & 2 & 10 & 8 & 66.6 & 4 \\
\hline
\end{tabular}

Data are expressed as 'n' with proportions (\%)

Table 6: Correlation between size of ectopic gestation mass and treatment outcome.

\begin{tabular}{|c|c|c|c|c|c|c|c|c|c|c|}
\hline $\begin{array}{l}\text { S. } \\
\text { no }\end{array}$ & $\begin{array}{l}\text { Size of the } \\
\text { mass on } \\
\text { TVS (cm) }\end{array}$ & $\mathrm{n}=\mathbf{3 4}$ & $\begin{array}{l}\text { Single } \\
\text { dose } \\
(n=21)\end{array}$ & $\%$ & $\begin{array}{l}\text { Multiple } \\
\text { dose } \\
(\mathbf{n}=13)\end{array}$ & $\%$ & $\begin{array}{l}\text { Treatment } \\
\text { success } \\
(n=29)\end{array}$ & $\%$ & $\begin{array}{l}\text { Treatment } \\
\text { failure } \\
(n=5)\end{array}$ & $\%$ \\
\hline 1 & $<3.5$ & 28 & 21 & 75 & 7 & 25 & 26 & 92.9 & 2 & 7.14 \\
\hline 2 & $3.5-5$ & 6 & 0 & - & 6 & 100 & 3 & 50 & 3 & 50 \\
\hline
\end{tabular}

Data are expressed as ' $n$ ' with proportions (\%) 


\section{DISCUSSION}

EP is a life threatening emergency and could adversely affect the future reproductive potential of the affected women. Awareness regarding the risk factors of EP will aid in early diagnosis and management and those risk factors could serve as potential targets for intervention and modification. ${ }^{8}$

Various studies have documented that incidence of EP increases with maternal age. ${ }^{9-12}$ The mean age of our study group was $26.8 \pm 5$ years. Various other trials in their assessment of age as a risk factor for EP have reported contradicting results. Bouyer et al in a case control study had reported older age to be a significant risk factor for EP and that it was unlikely that the higher risk was due to higher probability of exposure to most other risk factors for EP in older women. ${ }^{12}$ It was hypothesized that age related changes in tubal function may delay ovum transport and cause tubal implantation. ${ }^{13}$

Three women $(8.8 \%)$ had prior spontaneous abortions in our study. The association between prior spontaneous abortion and risk of EP has been variably reported..$^{12,14,15} \mathrm{It}$ was observed that risk of EP was considerably high in women with 3 or more abortions and this could possibly be attributed to infections secondary to spontaneous abortions. ${ }^{12,14}$ Higher risk could also be due to other risk factors common for EP and spontaneous abortions such as chromosomal abnormalities or hormonal factors. ${ }^{16,17}$ Prior medically induced abortion was also observed to be a risk factor for EP and could be due to lack of routine antibiotic prophylaxis in such group of women. ${ }^{12}$ But Banhart et al have reported no such association. ${ }^{4}$

Infertility as a risk factor was observed in $4(11.8 \%)$ women in our study of whom 1 had undergone assisted reproductive techniques (ART). ART have traditionally been believed to increase the risk of EP..$^{1,18}$ Though rapid advances in ART over the years have considerably decreased the incidence of EP following ART, techniques such as multiple embryo transfer can lead to increased risk. ${ }^{19}$ Fresh nondonor cycles had the highest EP rates compared to donor cycle and frozen thawed cycles. ${ }^{19,20}$ Invitro fertilization and embryo transfer has also been identified to be a risk factor for EP specifically in women with tubal infertility. ${ }^{21,22}$

Two out of 34 women (5.9\%) had history of prior IUD use in the current study. Prior IUD usage was reported to have a direct etiological role in EP and also through an association with infection, but Barnhat et al found no evidence to link prior IUD use with risk of EP. ${ }^{4,12,23,24}$ IUD does not inhibit ovulation and hence it is not effective in preventing extrauterine pregnancies. Risk of EP increased following failure of most contraceptives including IUD used in current cycle. ${ }^{21}$

In this study, 5.9\% were treated for PID in the past and $11.8 \%$ had undergone tubal surgeries. Several trials have reported an association between pelvic infection and EP. ${ }^{10,12,21,25}$ probably due to a causal link. This was also evidenced in a study in Sweden which reported that declining rates of chlamydial infections were accompanied by a fall in rates of EP. ${ }^{26}$ Many studies have also reported that factors like prior EP, prior tubal surgery, documented tubal pathology, in- utero exposure to DES to be strongly linked to risk of EP. ${ }^{4,12,15,21}$ Recurrence of EP may be due to persistent tubal pathology and the risk of repeated EP increases in direct proportion to the number of previous ectopic pregnancies. ${ }^{4}$

\section{Medical management of EP}

Major advances in the diagnosis and management of EP in the last 2 decades has led to early diagnosis, enabling a subset of women with EP to be treated with medical therapy thereby preserving future fertility. It is imperative that diagnostic and management strategies are clearly documented, keeping in mind the risk of ruptured EP. ${ }^{22}$ MTX is a folic acid antagonist, which prevents proliferation of cytotrophoblasts and reduces cell viability and $\beta$ hCG secretion.

In our study, $61.8 \%$ of women were successfully treated with single dose MTX and $23.5 \%$ with 2 doses. The overall success rate of MTX therapy was $85.3 \%$ and this was consistent with several other trials. ${ }^{27-29}$ Single dose MTX has been recommended to be most appropriate for women with relatively low pretreatment $\beta$ hCG levels and the 2 dose regimen in those with high pretreatment $\beta$ hCG levels. ${ }^{5,27,30}$ The 2 dose regimen minimizes the number of injections and surveillance methods compared to multiple dose regimen. The cut off value for pretreatment $\beta$ hCG which predicted treatment success has been variably reported and there is no consensus on it. ${ }^{5,31-34}$ In our study the success rate of MTX was $100 \%$ when $\beta$ hCG levels were $<1500 \mathrm{mIU} / \mathrm{ml}$ and $90 \%$ when $\beta$ hCG levels were between 1500 and $3000 \mathrm{mIU} / \mathrm{ml}$ and it declined to $66.7 \%$ when $\beta$ hCG levels exceeded $3000 \mathrm{mIU} / \mathrm{ml}$. The commonly identified predictors of MTX treatment failures are the presence of fetal cardiac activity, size of ectopic gestational mass of $>4 \mathrm{~cm}$, initial $\beta \mathrm{hCG}$ concentration of $>5000 \mathrm{mIU} / \mathrm{ml}$, increase in $\beta$ hCG concentration of $>50 \%$ in 48 hours before MTX, and continued rapid increase in $\beta$ hCG concentration during MTX therapy. ${ }^{30}$ The change in $\beta$ hCG levels between day 1 and day 4 was also found to be an early and effective predictor of success of MTX therapy by Zhang et al..$^{35}$ Single dose regimen was found to be less expensive, requires less intense monitoring and does not require citrovorum rescue. ${ }^{27}$ We found MTX therapy to be successful in $93 \%$ when the ectopic mass was $<3.5 \mathrm{~cm}$, while it was only $50 \%$ when the ectopic mass was $>3.5 \mathrm{~cm}$ and it was consistent with that reported by Dhar et al. ${ }^{36}$ Single dose MTX protocol was stated to be associated with fewer side effects. ${ }^{27}$ In our study 4 women (11.8\%) developed minor side effects like nausea and vomiting and none developed any serious side effects. Some trials comparing single versus multiple fixed dose regimen found no significant difference in either treatment 
success or rates of serious side effects ${ }^{32}$ while some others found multiple fixed dose regimen to be more effective. ${ }^{27,29,30,32,37,38}$

The significance of association between the risk factors detected in our study and EP cannot be commented upon as ours was not a case control study and that was a limitation.

\section{CONCLUSION}

MTX therapy in carefully selected unruptured tubal ectopic pregnancies is safe and effective. The success rate of MTX therapy was $85.3 \%$ with our management protocol. MTX was most effective when pretreatment. $\beta$ hCG levels were less than $1500 \mathrm{mIU} / \mathrm{ml}$. Need for surgical intervention should be anticipated when pretreatment $\beta$ hCG levels are high.

\section{Funding: No funding sources}

Conflict of interest: None declared

Ethical approval: The study was approved by the Institutional Ethics Committee

\section{REFERENCES}

1. Farquhar CM. Ectopic pregnancy. Lancet. 2005;366(9485):583-91.

2. Tahmina S, Daniel M, Solomon P. Clinical Analysis of Ectopic Pregnancies in a Tertiary Care Centre in Southern India: A Six-Year Retrospective Study. J Clin Diagn Res. 2016;10(10):13-6.

3. FOGSI GCPR on Ectopic pregnancy. Available at: https://www.google.com/url?sa=t\&rct=j\&q=\&esrc=s $\&$ source $=$ web $\& c d=\& c a d=$ rja\&uact $=8 \&$ ved $=2$ ahUK EwjRrfSOvNv1AhXr5nMBHdsrBj4QFnoECBMQA Q\&url=https\%3A\%2F\%2Fwww.fogsi.org\%2Fwpcontent $\% 2$ Fuploads $\% 2 F g c p r \% 2 F E c t o p i c-$ Pregnancy.pdf\&usg=AOvVaw3oAyEpSCNJGdW39 OizzSM1. Accessed on 27 September 2020.

4. Barnhart KT, Sammel MD, Gracia CR, Chittams J, Hummel AC, Shaunik A. Risk factors for ectopic pregnancy in women with symptomatic first-trimester pregnancies, Fertil Steril. 2006;86(1):36-43.

5. Committee on Practice bulletins- Gynecology. ACOG Practice bulletin No.191 summary: tubal ectopic pregnancy. Obstet Gynecol. 2018;131(2):409-11.

6. Ectopic pregnancy and miscarriage: diagnosis and initial management NICE guideline. 2019. Available at: www.nice.org.uk/guidance/ng126. Accessed on 27 September 2020.

7. Barnhart KT, Fay CA, Suescum M, Sammel MD, Appleby D, Shaunik A, Dean AJ. Clinical factors affecting the accuracy of ultrasonography in symptomatic first-trimester pregnancy. Obstet Gynecol. 2011;117(2):299-306.

8. Karaer A, Avsar FA, Batioglu S. Risk factors for ectopic pregnancy: a case-control study. Aust N Z J Obstet Gynaecol. 2006;46(6):521-7.
9. Atrash HK, Hughes JM, Hogue CJ. Ectopic pregnancy in the United States, 1970-1983. MMWR CDC Surveill Summ. 1986;35(2):29-37.

10. Coste J, Job-Spira N, Fernandez H, Papiernik E, Spira A. Risk factors for ectopic pregnancy: a case-control study in France, with special focus on infectious factors. Am J Epidemiol. 1991;133(9):839-49.

11. Westrom L, Bengtsson LP, Mardh PA. Incidence, trends and risks of ectopic pregnancy in a population of women. $\mathrm{Br}$ Med J (Clin Res $\mathrm{Ed}$ ). 1981;282(6257):15-8.

12. Bouyer J, Coste J, Shojaei T, Pouly JL, Fernandez H, Gerbaud L, Job-Spira N. Risk factors for ectopic pregnancy: a comprehensive analysis based on a large case-control, population-based study in France. Am J Epidemiol. 2003;157(3):185-94.

13. Yeko TR, Handler A. The effect of aging on tubal function and ectopic pregnancy. Semin Reprod Endocrinol. 1991;9:215-20.

14. Doyle MB, DeCherney AH, Diamond MP. Epidemiology and etiology of ectopic pregnancy. Obstet Gynecol Clin North Am. 1991;18(1):1-17.

15. Ankum WM, Mol BW, Van der Veen F, Bossuyt PM. Risk factors for ectopic pregnancy: a meta-analysis. Fertil Steril. 1996;65(6):1093-9.

16. Job-Spira N, Coste J, Bouyer J, Tharaux-Deneux C, Fernandez H. Chromosomal abnormalities and ectopic pregnancy? New directions for aetiological research. Hum Reprod. 1996;11(2):239-42.

17. Fernandez H, Bouyer J, Coste J. The hidden side of ectopic pregnancy: the hormonal factor. Hum Reprod. 1996;11:243-4.

18. Marion LL, Meeks GR. Ectopic pregnancy: History, incidence, epidemiology, and risk factors. Clin Obstet Gynecol. 2012;55(2):376-86.

19. Perkins KM, Boulet SL, Kissin DM, Jamieson DJ; National ART Surveillance (NASS) Group. Risk of ectopic pregnancy associated with assisted reproductive technology in the United States, 20012011. Obstet Gynecol. 2015;125(1):70-8.

20. Decleer W, Osmanagaoglu K, Meganck G, Devroey P. Slightly lower incidence of ectopic pregnancies in frozen embryo transfer cycles versus fresh in vitro fertilization-embryo transfer cycles: a retrospective cohort study. Fertil Steril. 2014;101(1):162-5.

21. Li C, Zhao WH, Zhu Q, Cao SJ, Ping H, Xi X, et al. Risk factors for ectopic pregnancy: a multi-center case-control study. BMC Pregnancy Childbirth. 2015;15:187.

22. Sivalingam VN, Duncan WC, Kirk E, Shephard LA, Horne AW. Diagnosis and management of ectopic pregnancy. J Fam Plann Reprod Health Care. 2011;37(4):231-40.

23. Westrom L, Bengtsson LP, Mardh PA. The risk of Pelvic inflammatory disease in women using intrauterine contraceptive devices compared to nonusers. Lancet. 1976;2:221-4.

24. Vessey MP, Yeates D, Flave IR. Pelvic inflammatory disease and the intrauterine device: findings of large cohort study. Br Med J. 1981;282:855-7. 
25. Tay JI, Moore J, Walker JJ. Ectopic pregnancy. BMJ. 2000;320(7239):916-9.

26. Egger M, Low N, Smith GD, Lindblom B, Herrmann B. Screening for chlamydial infections and the risk of ectopic pregnancy in a county in Sweden: ecological analysis. BMJ. 1998;316(7147):1776-80.

27. Barnhart KT, Gosman G, Ashby R, Sammel M. The medical management of ectopic pregnancy: a metaanalysis comparing "single dose" and "multidose" regimens. Obstet Gynecol. 2003;101(4):778-84.

28. Stovall TG, Ling FW. Single-dose methotrexate: an expanded clinical trial. Am J Obstet Gynecol. 1993;168(6):1759-62.

29. Gungorduk K, Asicioglu O, Yildirim G, Gungorduk OC. Comparison of single-dose and two-dose methotrexate protocols for the treatment of unruptured ectopic pregnancy. J Obstet and Gynaecol. 2011;31(4):330-4.

30. Practice Committee of American Society for Reproductive Medicine. Medical treatment of ectopic pregnancy: a committee opinion. Fertil Steril. 2013;100(3):638-44.

31. Pulatoglu C, Dogan O, Basbug A, Kaya Ae, Yildiz A, Temizkan O. Predictive factors of methotrexate treatment success in ectopic pregnancy: A singlecenter tertiary study. North Clin Istanb. 2018;5(3):227-31.

32. Mol F, Mol BW, Ankum WM, Veen FV, Hajenius PJ. Current evidence on surgery, systemic methotrexate and expectant management in the treatment of tubal ectopic pregnancy: a systematic review and metaanalysis. Human Reprod Update. 2008;14(4):309-19.

33. Bonin L, Pedreiro C, Moret S, Chene G, Gaucherand P, Lamblin G. Predictive factors for the methotrexate treatment outcome in ectopic pregnancy: A comparative study of 400 cases. Eur J Obstet Gynecol Reprod Biol. 2017;208:23-30.

34. Levin G, Saleh NA, Haj-Yahya R, Matan LS, Avi B. Predicting success of methotrexate treatment by pretreatment HCG level and 24-hour HCG increment. Int J Gynaecol Obstet. 2018;141(1):70-3.

35. Zhang J, Zhang Y, Gan L, Liu XY, Du SP. Predictors and clinical features of methotrexate (MTX) therapy for ectopic pregnancy. BMC Pregnancy Childbirth. 2020;20(1):654.

36. Dhar H, Hamidi I, Rathi B. Methotrexate Treatment of Ectopic pregnancy: Experience at Nizwa Hospital Literature Review. Oman Med J. 2011;26(2):94-8.

37. Lipscomb GH, McCord ML, Stovall TG, Huff G, Portera SG, Ling FW. Predictors of success of methotrexate treatment in women with tubal ectopic pregnancies. N Engl J Med. 1999;341(26):1974-8.

38. Alleyassin A, Khademi A, Aghahosseini M, Safdarian L, Badenoosh B, Hamed EA. Comparison of success rates in the medical management of ectopic pregnancy with single-dose and multiple-dose administration of methotrexate: a prospective, randomized clinical trial. Fertil Steril. 2006;85(6):1661-6.

Cite this article as: Amudha P, Shenbagam G, Raji C. Analysis of risk factors and treatment outcome following methotrexate therapy in ectopic pregnancy. Int J Reprod Contracept Obstet Gynecol 2022;11:746-51. 